\title{
Habitat determines plant community responses to climate change in the High Arctic ${ }^{1}$
}

\author{
M.A. Mörsdorf and E.J. Cooper
}

\begin{abstract}
Plant climate responses may depend on site-specific environmental context. Using fences and open-top chambers, we enhanced snow depth (creating Ambient, Medium, and Deep regimes) over an 11-year period and increased temperatures for two summers in dry heath and mesic meadow habitats on Svalbard, Norway. Comparison of plant growth form abundance and diversity responses in these two habitats showed that the response was more limited in the dry heath than in the mesic meadow. Common to both habitats was a decrease in shrub abundance and vascular plant species richness in the Deep snow regimes. Bryophyte abundance increased with enhanced snow cover in both habitats, but only up to a certain extent of snow depth in the meadow. However, for many growth forms, the effects of snow enhancement were habitat specific. In the mesic meadow, the abundance of forbs and bryophytes increased with snow enhancement, but the effect was stronger when combined with summer warming. The "bryofication" - that is, an increased abundance of bryophytes in response to snow enhancement and summer warming - also influenced overall plant diversity in the mesic meadow. Bryophytes are species-rich taxa and may respond differently than vascular plants to environmental change. We show that the inclusion of even the most common bryophytes in measures of diversity may determine overall plant diversity responses to environmental change in the Arctic.
\end{abstract}

Key words: snow fence, open-top chamber, context dependency, plant growth form, bryophytes.

Résumé : Les réponses des plantes au climat peuvent dépendre d'un contexte environnemental spécifique au site. En utilisant des clôtures et des chambres à toit ouvert, les auteurs ont augmenté l'épaisseur de la neige (en créant des régimes ambiant, moyen et profond) pendant 11 ans et augmenté les températures pendant deux étés au Svalbard, Norvège. La comparaison des réponses en matière d'abondance et de diversité des formes de croissance des plantes dans deux habitats a montré que la réponse était plus limitée dans la lande sèche que dans la prairie mésique. Dans les deux habitats, ils ont constaté une diminution de l'abondance des arbustes et de la richesse des espèces de plantes vasculaires dans les régimes de neige profonds. L'abondance des bryophytes augmentait avec l'augmentation du régime d'enneigement dans les deux habitats, mais seulement jusqu'à une certaine profondeur de neige dans la prairie. Cependant, pour de nombreuses formes de croissance, les effets de l'augmentation de la neige étaient spécifiques à l'habitat. Dans la prairie mésique, l'abondance des plantes herbacées non graminoïdes et des bryophytes augmentait avec l'augmentation de l'enneigement, mais elle était plus forte si elle était associée à un réchauffement estival. La «bryofication », c'est-à-dire l'augmentation de l'abondance des

Received 9 November 2020. Accepted 8 April 2021.

M.A. Mörsdorf* and E.J. Cooper. Department of Arctic and Marine Biology, UiT - The Arctic University of Norway, 9037 Tromsø, Norway.

Corresponding author: Martin A. Mörsdorf (e-mail: martin.moersdorf@biologie.uni-freiburg.de).

${ }^{1}$ This paper is part of a Special Issue entitled: Impacts of climate change on tundra ecosystems: Three decades of results from the International Tundra Experiment (ITEX).

*Present address: Geobotany Group, Institute for Biology II, Albert-Ludwigs-Universität Freiburg, 79104 Freiburg, Germany. Copyright remains with the author(s) or their institution(s). This work is licensed under a Creative Attribution 4.0 International License (CC BY 4.0) http://creativecommons.org/licenses/by/4.0/deed.en_GB, which permits unrestricted use, distribution, and reproduction in any medium, provided the original author(s) and source are credited. 
bryophytes en réponse à l'augmentation de l'enneigement et au réchauffement estival, influençait aussi la diversité végétale globale de la prairie mésique. Les bryophytes sont des taxons riches en espèces et peuvent répondre de manière différente des plantes vasculaires aux changements environnementaux. Les auteurs montrent que même l'inclusion des bryophytes les plus communes dans les mesures de diversité peut donc déterminer les réponses de la diversité végétale globale aux changements environnementaux dans l'Arctique. [Traduit par la Rédaction]

Mots-clés : barrière de neige, chambre à toit ouvert, dépendance au contexte, forme de croissance des plantes, bryophytes.

\section{Introduction}

Large Arctic areas are predicted to have increasingly snowy winters and warm summers (ACIA 2005; Saha et al. 2006). Deeper snow affects nutrient cycling (Schimel et al. 2004) and may delay snowmelt and the onset of the growing season (Callaghan et al. 2011). Such changes affect phenology (van der Wal et al. 2000; Semenchuk et al. 2013), reproductive success (Semenchuk et al. 2013, 2016b), and productivity of some species (Rumpf et al. 2014), which ultimately changes the structure and diversity of plant communities (Wahren et al. 2005; Wipf and Rixen 2010). Some Arctic species of plants profit from warmer summers (Elmendorf et al. 2012a), while others disappear (Callaghan et al. 2004; CAFF 2013), thus changing the vegetation in these communities. Several experimental studies have tried to infer generalities about Arctic plant growth form responses to climate change, but the "winners" and "losers" are still unknown, since growth forms respond differently in various habitats among and within study areas.

Manipulation of Arctic snow has promoted contrasting community structure responses at different sites, as shown by Wipf and Rixen (2010) and the studies summarized in Table 1 . These highly site-specific outcomes imply that general statements about vegetation responses to enhanced snow cannot be made. These studies also suggest that the direction of responses may depend on a plant's position along an environmental gradient, and may differ between habitats within the same site, as has been shown in Alaska (e.g., Wahren et al. 2005). Modifications of the habitat-specific moisture regime during the growing season in Arctic tundra are therefore likely to play a role in determining the responses of community structure to enhanced snow (Leffler et al. 2016; Cooper et al. 2019), as has also been found in alpine communities (e.g., Knight et al. 1979). However, short-term responses of community structure to experimentally enhanced snow cover may also be different from long-term responses (Natali et al. 2014), and there is little experimental evidence from studies that have assessed changes in Arctic vegetation structure over a time period of more than a decade (Leffler et al. 2016). Furthermore, long-term responses to enhanced snow depth might be modified by warmer summer air temperatures (Leffler et al. 2016). Atmospheric heating in the summer is associated with shrub expansion throughout the Arctic (Myers-Smith et al. 2011; Elmendorf et al. 2012a), yet experiments show that such trends depend on soil moisture and the duration of the manipulation (Elmendorf et al. $2012 b$ ). Long-term responses of vegetation structure to climate change might also affect plant diversity, because some growth forms are important niche constructors in tundra, and any abundance change may affect local vascular plant species richness (Bråthen and Ravolainen 2015). Experimental snow enhancements in alpine tundra indicated that diversity often declines with a deeper and longer snow cover (Wipf and Rixen 2010). Similar trends have been shown for the Arctic, but only if enhanced snow depth promoted shrub abundance, causing more shading and an exclusion of small-stature forb or bryophyte species (Wahren et al. 2005). However, habitat-specific responses of long-term plant 
Table 1. Plant growth form responses to experimentally increased winter snow depth in different habitats.

\begin{tabular}{|c|c|c|c|c|}
\hline Plant growth form & Response & Habitat & Site & Reference \\
\hline Evergreen shrubs & $\begin{array}{l}\text { None } \\
\text { Increase } \\
\text { Decrease } \\
\text { Decrease }\end{array}$ & $\begin{array}{l}\text { Moist tussock tundra } \\
\text { Mesic lower shrub tundra } \\
\text { Moist tussock tundra } \\
\text { Dry heath and moist meadow }\end{array}$ & $\begin{array}{l}\text { Eight Mile Lake, Alaska, USA } \\
\text { Daring Lake, Northwest Territories, Canada } \\
\text { Toolik Lake, Alaska, USA } \\
\text { Adventdalen, Svalbard, Norway }\end{array}$ & $\begin{array}{l}\text { Natali et al. } 2014 \\
\text { Christiansen et al. } 2018 \\
\text { Wahren et al. } 2005 \\
\text { Cooper et al. } 2019\end{array}$ \\
\hline Deciduous shrubs & $\begin{array}{l}\text { None } \\
\text { None } \\
\text { Increase } \\
\text { Decrease }\end{array}$ & $\begin{array}{l}\text { Moist tussock tundra } \\
\text { Mesic lower shrub tundra } \\
\text { Moist tussock tundra } \\
\text { Dry heath and moist meadow }\end{array}$ & $\begin{array}{l}\text { Eight Mile Lake, Alaska, USA } \\
\text { Daring Lake, Northwest Territories, Canada } \\
\text { Toolik Lake, Alaska, USA } \\
\text { Adventdalen, Svalbard, Norway }\end{array}$ & $\begin{array}{l}\text { Natali et al. } 2014 \\
\text { Christiansen et al. 2018; Zamin and Grogan } 2012 \\
\text { Wahren et al. 2005; Leffler et al. } 2016 \\
\text { Cooper et al. } 2019\end{array}$ \\
\hline Graminoids & $\begin{array}{l}\text { Increase } \\
\text { Increase } \\
\text { Decrease } \\
\text { Decrease }\end{array}$ & $\begin{array}{l}\text { Moist tussock tundra } \\
\text { Lowland peat plateau } \\
\text { Moist tussock tundra } \\
\text { Dry heath and moist meadow }\end{array}$ & $\begin{array}{l}\text { Eight Mile Lake, Alaska, USA } \\
\text { Storflaket, Abisko, Sweden } \\
\text { Toolik Lake, Alaska, USA } \\
\text { Adventdalen, Svalbard, Norway }\end{array}$ & $\begin{array}{l}\text { Natali et al. } 2014 \\
\text { Johansson et al. } 2013 \\
\text { Leffler et al. } 2016 \\
\text { Cooper et al. } 2019\end{array}$ \\
\hline Forbs & $\begin{array}{l}\text { None } \\
\text { None } \\
\text { None }\end{array}$ & $\begin{array}{l}\text { Mesic lower shrub tundra } \\
\text { Moist tussock tundra } \\
\text { Dry heath and moist meadow }\end{array}$ & $\begin{array}{l}\text { Daring Lake, Northwest Territories, Canada } \\
\text { Toolik Lake, Alaska, USA } \\
\text { Adventdalen, Svalbard, Norway }\end{array}$ & $\begin{array}{l}\text { Christiansen et al. } 2018 \\
\text { Wahren et al. } 2005 \\
\text { Cooper et al. } 2019\end{array}$ \\
\hline Bryophytes & $\begin{array}{l}\text { None } \\
\text { None } \\
\text { Increase } \\
\text { Increase }\end{array}$ & $\begin{array}{l}\text { Moist tussock tundra } \\
\text { Lowland peat plateau } \\
\text { Moist tussock tundra } \\
\text { Dry heath and moist meadow }\end{array}$ & $\begin{array}{l}\text { Eight Mile Lake, Alaska, USA } \\
\text { Storflaket, Abisko, Sweden } \\
\text { Toolik Lake, Alaska, USA } \\
\text { Adventdalen, Svalbard, Norway }\end{array}$ & $\begin{array}{l}\text { Natali et al. } 2014 \\
\text { Johansson et al. } 2013 \\
\text { Wahren et al. } 2005 \\
\text { Cooper et al. } 2019\end{array}$ \\
\hline
\end{tabular}


diversity to year-round climate change remain poorly investigated in the Arctic. Existing assessments often lack information on bryophyte diversity (Elmendorf et al. 2012b), but including bryophytes in diversity measures may be important, since these plants respond to both winter and summer changes at some Arctic sites (Elmendorf et al. 2012b; Cooper et al. 2019).

In this study, we assessed environmental context dependencies of vegetation responses to enhanced winter snow depths in the High Arctic. We also tested potential interaction effects of long-term snow enhancement and short-term summer warming. Snow manipulations were conducted for 11 years, and summer air temperatures were increased for two summers during the course of the experiment, using open-top chambers (OTCs) (Marion et al. 1997). Within our study area on Svalbard, Norway, we compared plant growth form abundances and diversity in two nearby habitat types: a relatively dry heath and a comparably mesic meadow. We hypothesized that (H1) long-term snow enhancement would cause a change in the abundance of major plant growths forms within the community, including shrubs, graminoids, forbs, and bryophytes. We also hypothesized that the abundance of lichens may be adversely affected by a deeper and prolonged snow cover (Scott and Rouse 1995; Christiansen et al. 2018). However, based on contrasting evidence presented from the literature (as described earlier), we expected the direction and magnitude of responses in each growth form to be habitat specific and potentially different between our dry heath and mesic meadow habitats. Second (H2), we hypothesized that plant responses to snow depth may interact with short-term increases in summer air temperatures, but also that the effects may depend on the habitat type of investigation. Third (H3), in accordance with growth form responses to climate change scenarios, we expected to observe changes in within-community plant diversity. In situations where treatment responses of bryophytes are different from those of vascular plants, we expected different responses of vascular plant diversity and overall plant diversity of the community.

\section{Materials and methods}

Field site and experimental setup

Our study was conducted in a High Arctic valley site on Svalbard, Norway $\left(78^{\circ} 10^{\prime} \mathrm{N}, 16^{\circ} 04^{\prime} \mathrm{E}\right)$. The overall vegetation in the area is classified as prostrate dwarf-shrub, herb tundra (CAVM Team 2003). However, in a more detailed classification, Elvebakk (2005) defined the vegetation as part of the middle Arctic tundra, with two distinct habitat types: heath and meadow. Heath is described as relatively dry and well-drained Cassiope tetragona (L.) D. Don heath sloping slightly down towards Advent River in the North, while meadow consists of flat and less-well drained mesic Dryas octopetala L. - Tomentypnum nitens (Hedw.) Loeske meadows overlying peat and shale-derived gelisols (Lupascu et al. 2018).

Mean annual precipitation and temperature for $2009-2018$ was $228 \mathrm{~mm}$ and $-2.5^{\circ} \mathrm{C}$, respectively. The coldest month was March $\left(-10.6^{\circ} \mathrm{C}\right)$ and the warmest was July $\left(7.4^{\circ} \mathrm{C}\right)$ (https://seklima.met.no/). The geological parental material in the valley bottom consists of basic calcareous sand, silt, and shale stones, which originated from Mesozoic sedimentary bedrocks (Hjelle 1993; Tolgensbakk et al. 2000). Soils typically have an organic layer, which is followed by A horizons reaching down to a maximum depth of $10 \mathrm{~cm}$, followed by the $\mathrm{B} / \mathrm{C}$ horizons (Strebel et al. 2010). Soil pH typically ranges between 5 and 6.5. The area is underlain by continuous permafrost, which had a mean active layer depth of $105 \mathrm{~cm}$ between 2000 and 2007 (Morgner et al. 2010).

The experiment was set up in the flat valley bottom, within an altitude between 25 and $80 \mathrm{~m}$ above sea level. The experimental manipulations within the site were established in 2006 to assess the effects of altered winter snow regimes on Arctic vegetation (Cooper et al. 2011). Snow fences were set up and placed perpendicularly to the main wind 
direction (southeast), trapping snow in the leeward side of the fence. The fences were spatially distributed within four experimental blocks. Two blocks were placed within dry heath and two blocks within mesic meadow. The blocking caused fences from different blocks to be spread more than $500 \mathrm{~m}$ apart from each other, covering a total area of $\sim 2.5 \mathrm{~km} \times 1.5 \mathrm{~km}$. Three snow fences, each $1.5 \mathrm{~m}$ high and $6.2 \mathrm{~m}$ long, were erected within each block. Snow accumulates to a maximum depth of $\sim 150 \mathrm{~cm}$ within a zone of 3-12 $\mathrm{m}$ behind the fence, an area henceforth termed "Deep". Further away (up to $20 \mathrm{~m}$ behind the fence), snow accumulates to a maximum of $\sim 100 \mathrm{~cm}$, which is henceforth termed "Medium". Finally, "Ambient" areas with natural snow deposition (maximum of $\sim 35 \mathrm{~cm}$ ) are found adjacent to, but are not affected by, the fences. The vegetation in the location of fences and unmanipulated areas were visually estimated to be comparable before the fences were established. Temperature loggers (Gemini, Tinytag data logger, model TGP-4020, UK), which were installed just below the soil surface in each snow regime around each fence, recorded temperatures at $30 \mathrm{~min}$ intervals since the start of the experiment. Previous studies have showed that soils in enhanced snow regimes are warmer during the winter, with melt out delayed by 1-3 weeks compared with snow in the Ambient regime (Semenchuk et al. 2013; Mörsdorf et al. 2019). Meadow takes longer to drain after snowmelt and retains more soil moisture than does heath (Cooper et al. 2011), and enhanced snow regimes lead to habitats that have greater moisture than those in Ambient regimes, especially at the start of the growing season (Mörsdorf et al. 2019).

At the start of the experiment, six spots were randomly selected within each Deep and Ambient snow regime to establish $75 \mathrm{~cm} \times 75 \mathrm{~cm}$ vegetation plots for long-term monitoring. Half of those plots were stratified to contain Dryas octopetala as a focal plant species and the other half Cassiope tetragona (Cooper et al. 2011). In 2010, three further plots were established by random choice within the Medium regime, containing both of the two focal species. This study only concerns data from plots with Dryas octopetala as a focal species (in Ambient and Deep) and the Medium plots. At snowmelt in 2015 and 2017, we additionally erected OTCs with a $2 \mathrm{~m}$ diameter to enhance summer temperatures (Marion et al. 1997). OTCs were placed out when plots in the respective snow regimes were snow free, and they were removed at the end of the growing season. At each fence, an OTC was placed on a randomly selected Ambient and Deep Dryas octopetala plot and a Medium plot.

The species present in the two vegetation types were quite similar, but the vegetation cover and dominant species differed (Supplementary Table S1 ${ }^{1}$ ). Dominant vascular plant species in the heath plots were as follows (highest live abundance first): Dryas octopetala, Salix polaris Wahlenb., Cassiope tetragona; in the meadow plots: Dryas octopetala, Alopecurus borealis Trin., Salix polaris, Luzula confusa Lindeb., and Bistorta vivipara (L.) Delarbre. The dominant mosses in the heath habitat were Sanionia uncinata (Hedw.) Loeske, Tomenthypnum nitens (Hedw.) Loeske, Hylocomium splendens (Hedw.) Schimp., Dicranum spp., and Distichium spp.. The dominant mosses in the meadow habitat were Sanionia uncinata, Polytrichum spp., Aulacomnium spp., Tomentypnum nitens, and Hylocomium splendens.

\section{Recordings of plant community and environmental data}

Between 3 and 31 July 2017, we assessed plant community properties within the experiment. We used the point intercept method (Jonasson 1988) within a $75 \mathrm{~cm} \times 75 \mathrm{~cm}$ square frame placed over the permanent vegetation plot. The frame was split up into 100 regularly distributed subsquares using strings. The strings were aligned in parallel in two horizontal levels. At each point where the strings crossed, we registered vegetation by aligning the two

\footnotetext{
${ }^{1}$ Supplementary material is available with the article at https://doi.org/10.1139/as-2020-0054.
} 
parallel strings and recording the plant species at that point. Recordings were done throughout the canopy layer by carefully moving the higher vegetation layers aside and noting species within all subsequent vegetation layers at this point ("all hits"). For the community assessment within each plot, we recorded living vascular plants to species level. For woody plants, we distinguished live from dead plant material when dead branches easily broke off the main plant as soon as they were touched. We were able to confidently identify some bryophytes and lichens to species level in the field. Bryophytes and lichens were found below the canopy of vascular plants; for each of the 100 points, we noted all species that were found in an approximate radius of $1 \mathrm{~cm}$ around the respective point. Each bryophyte species could therefore yield a maximum of 100 hits in each plot. Owing to practical considerations, species within the groups that could not be identified without microscopy in the lab had to be identified at the genus level only. Bryophytes for which we could not guarantee a secure identification to the genus level in the field had to be combined into one group of unidentified bryophytes, since we could not otherwise attain abundance estimates of those plants. We followed the same approach for all lichens within the plots. Crustose lichens were not further identified in our study. The taxonomic units we used in this study are shown in Table 2. Nomenclature for vascular plants follows the Panarctic flora (http://panarcticflora.org/). Nomenclature for bryophytes follows Prestø et al. (2014), and lichen nomenclature follows Øvstedal et al. (2009).

For this study, we used 10 of the original 12 fences, as two of the fences collapsed owing to breakage and soil subsidence. Since one of the fences (C8) had no Medium plots, it had only six (three Ambient and three Deep) instead of the planned nine plots. We therefore ended up with a total of 87 permanent vegetation plots: 10 fences $\times 3$ snow treatments $\times$ (2 non-OTC + 1 OTC) - 3 Medium plots missing at C8.

Temperature loggers (Gemini, Tinytag data logger, model TGP-4020, UK) were additionally installed below the soil surface within each OTC and recorded the temperature at $30 \mathrm{~min}$ intervals. We extracted temperature data for each snow and temperature regime for the period between 1 June and 31 July 2017 to represent soil temperatures during peak growing season. Volumetric soil moisture content was measured at each plot corner using a Theta Probe ML2x (Delta-T Devices, Cambridge, UK) once from 6 to 27 July 2017. Vegetation was not removed prior to probing.

\section{Statistical analysis}

We focused on analyzing growth forms rather than species in this study because we realized that it might not be possible to compare individual species responses at our site to those at other Arctic sites if a given species is absent. Furthermore, most species at our site were not frequently found in each plot, which would lead to highly unbalanced data and different replicates for different models.

To prepare our data for analysis, we first combined the hits of recorded live vegetation in each plot into growth forms (shrubs, graminoids, forbs, bryophytes, and lichens; see Table 2). The records of unidentified bryophytes and lichens were included in the respective groups here. Pteridophytes were patchily distributed with very low abundance, so we added these values to the "forbs" group in our analyses. We split the dataset according to plots within the heath and meadow habitats. To estimate group abundances and the effects of snow enhancement and summer warming, we used linear mixed effects models within $R$ (version 3.6.0), applying the lme function of the nlme package (Pinheiro and Bates 2000). For each group, we set the number of hits within a plot as the response variable, as it is representative of the abundance of each growth form within plots. The treatments of snow enhancement (Ambient, Medium, Deep) and summer warming (no OTC, OTC), including their two-way interaction, were defined as fixed effects. The snow fence location, and 
Table 2. Growth form of vascular plants, bryophytes, and lichens identified during the field campaign on Svalbard, Norway.

\begin{tabular}{|c|c|}
\hline Growth form & Species or genus \\
\hline \multicolumn{2}{|c|}{ Vascular plants } \\
\hline Shrub & Cassiope tetragona \\
\hline Shrub & Dryas octopetala \\
\hline Shrub & Salix polaris \\
\hline Graminoid & Alopecurus borealis \\
\hline Graminoid & Calamagrostis neglecta \\
\hline Graminoid & Carex rupestris \\
\hline Graminoid & Deschampsia alpina \\
\hline Graminoid & Festuca rubra \\
\hline Graminoid & Festuca viviparoidea \\
\hline Graminoid & Juncus biglumis \\
\hline Graminoid & Luzula nivalis \\
\hline Graminoid & Luzula confusa \\
\hline Graminoid & Poa arctica \\
\hline Graminoid & Trisetum spicatum \\
\hline Forb & Bistorta vivipara \\
\hline Forb & Cardamine bellidifolia \\
\hline Forb & Cerastium arcticum \\
\hline Forb & Draba alpina \\
\hline Forb & Koenigia islandica \\
\hline Forb & Micranthes hieraciifolia \\
\hline Forb & Minuartia biflora \\
\hline Forb & Oxyria digyna \\
\hline Forb & Papaver dahlianum \\
\hline Forb & Pedicularis hirsuta \\
\hline Forb & Ranunculus hyperboreus \\
\hline Forb & Ranunculus sulphureus \\
\hline Forb & Saxifraga сетпиа \\
\hline Forb & Saxifraga cespitosa \\
\hline Forb & Saxifraga hirculus \\
\hline Forb & Saxifraga oppositifolia \\
\hline Forb & Silene acaulis \\
\hline Forb & Stellaria longipes \\
\hline Pteridophyte & Equisetum arvense \\
\hline Pteridophyte & Equisetum variegatum \\
\hline \multicolumn{2}{|c|}{ Nonvascular plants } \\
\hline Bryophyte & Hylocomium splendens \\
\hline Bryophyte & Sanionia uncinata \\
\hline Bryophyte & Tomentypnum nitens \\
\hline Bryophyte & Aulacomnium spp. (incl. Aulacomnium turgidum and Aulacomnium palustre) \\
\hline Bryophyte & Dicranum spp. and Distichium spp. \\
\hline Bryophyte & Polytrichum spp. \\
\hline Bryophyte & Racomitrium spp. \\
\hline Bryophyte & Group of unidentified mosses (e.g., Plagiomnium spp., Pohlia spp., Bryum spp.) \\
\hline Bryophyte & Anthelia juratzkana \\
\hline Bryophyte & Ptilidium ciliare \\
\hline Bryophyte & Group of unidentified liverworts \\
\hline Lichen & Cetrariella delisei \\
\hline Lichen & Cetraria islandica \\
\hline Lichen & Thamnolia vermicularis \\
\hline Lichen & Cladonia spp. \\
\hline Lichen & Peltigera spp. \\
\hline Lichen & Stereocaulon spp. \\
\hline Lichen & Group of unidentified cetrariod lichens (e.g., Cetraria aculeata, Cetraria ericetorum) \\
\hline Lichen & Group of unidentified lichens \\
\hline
\end{tabular}

Note: All vascular plants could be identified to the species level in the field. Since we did not sample destructively, some bryophytes and lichens could only be identified to the genus level. 
the snow regime nested within fences, were defined as nested random variables to account for variation caused by the spatial hierarchy of the experimental setup. For each full model (including the interaction), we called the anova function in R. We kept the model structure to extract parameter estimates if the interaction term was marginally significant (10\% type 1 error rate). If the interaction term was not at least marginally significant, we simplified the model to include snow enhancement and summer warming as additive fixed effects. Analysis of variance (ANOVA) outputs of all full models are presented in Supplementary Tables S2-S6 ${ }^{1}$.

To estimate plant diversity within plots and the effects of snow enhancement and summer warming, we defined five diversity indices as follows: (1) the number of vascular plant species within each plot, representing vascular plant species richness; (2) the number of taxonomic bryophyte units that could be identified in the field (excluding unidentified bryophytes), representing an estimate of bryophyte richness; (3) the sum of vascular plant species and bryophyte richness, representing overall plant diversity; (4) the Shannon diversity index (SDI) based on vascular plant species; and (5) the SDI based on taxonomic bryophyte units. Each of the five diversity indices was set as a response variable, and we used the same modelling approach as that described for growth form abundances.

We also assessed treatment effects on soil temperatures and moisture during the 2017 growing season. Daily soil temperature means were averaged for the period 1 June 31 July 2017 for each data logger, and the four soil moisture measurements at each plot corner were averaged for each plot. We used the same modelling approach as that used for plant growth forms and diversity. Soil temperature models had only snow fence location as a random effect. For soil moisture models, we used the same random effects structure as that used for plant abundance and diversity models. We used diagnostic plots to assess all models in terms of outliers, homogeneous residuals, and normally distributed residuals. For all models, we declared the treatment effects of snow enhancement and summer warming as statistically significant if the $95 \%$ confidence intervals of the treatment effect sizes did not overlap with a value of zero.

\section{Results}

Effects of winter and summer treatments on soil environment during the 2017 growing season

In both habitats, growing season soil temperatures were strongly affected by interactions between snow treatment and summer warming. Heath soils tended to be cooler in Deep than in Ambient without OTC (Fig. 1a), but soil temperature was $3.5^{\circ} \mathrm{C}$ warmer with OTC (Fig. 1a). Meadow soils without OTCs were $4.3^{\circ} \mathrm{C}$ cooler in Medium and $4.6{ }^{\circ} \mathrm{C}$ cooler in Deep than in Ambient, whereas OTCs ameliorated this snow regime response and warmed soils by $3.1^{\circ} \mathrm{C}$ more in Deep versus Ambient (Fig. 1a). This led to a large temperature difference in both habitats between the OTC and non-OTC plots in Deep. Ambient temperatures in the meadow habitat appeared slightly higher than those in the heath.

Heath and meadow soil moisture values were not significantly affected by snow enhancement or by summer warming (Figs. $1 b$ and $1 c$ ), although there was a trend of moister soils under enhanced snow regimes. Soils in the meadow appeared moister than those in the heath.

Effects of winter and summer treatments on community structure

The two habitats differed in their vegetation composition, as well as the amount and direction of change due to treatment. 
Fig. 1. Soil environmental conditions within treatment categories during the 2017 growing season. (a) Estimates of mean soil temperatures between 1 June and 31 July 2017 (grey bars) and their 95\% confidence interval limits (whiskers) were deduced from linear mixed effects models. Statistically significant effects of snow enhancement in comparison to Ambient are marked with an asterisk $\left({ }^{*}, p<0.05\right)$ and are separately presented for plots without (dark grey) and with (light grey) summer warming. Interaction effects between snow enhancement and summer warming were not significant for estimated mean volumetric soil moisture content for $(b)$ dry heath and $(c)$ mesic meadow.

(a)

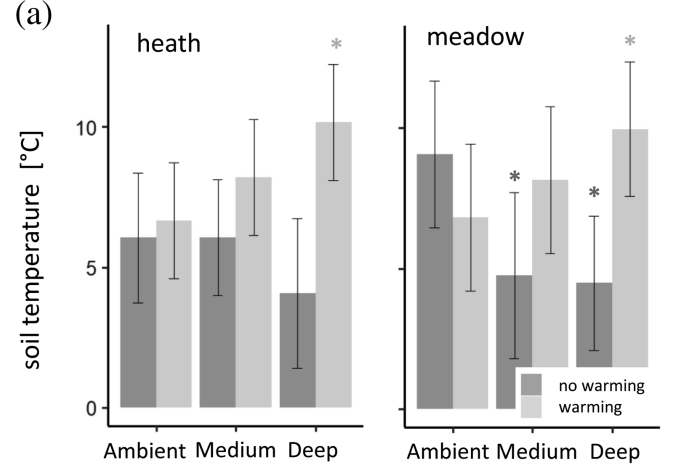

(b)

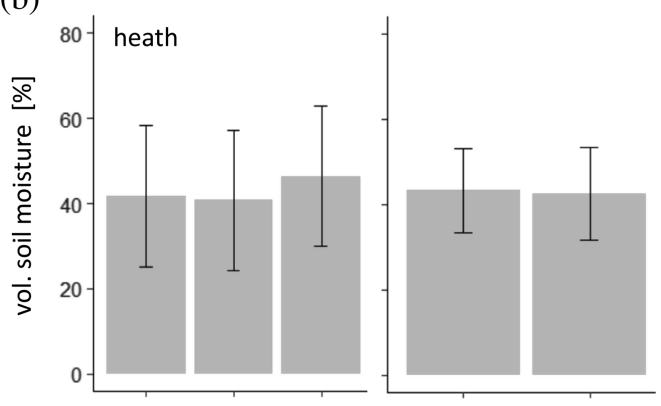

(c)

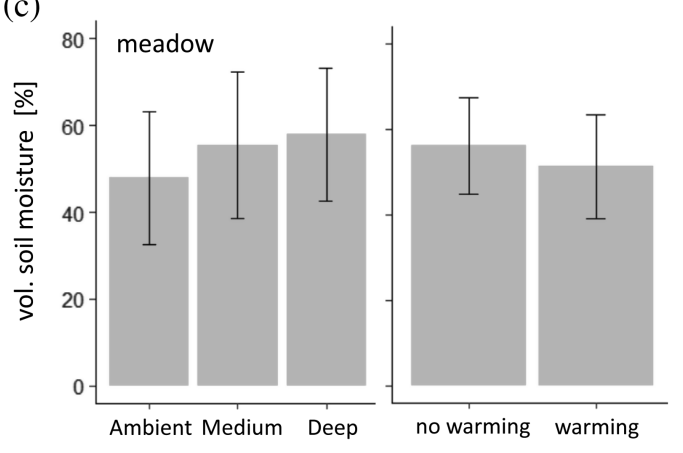

In the heath habitat, snow enhancement affected the plant growth form abundance of some groups, but the passive warming treatment during summer only affected forbs (Table 3). The abundance of shrubs was significantly lower in Deep than in Ambient (Fig. 2a), while forb abundances were higher in warmed plots (Fig. 2b). On the contrary, bryophyte abundance was significantly greater in Deep than in Ambient (Fig. 2c). Lichen abundance was not affected by snow regime or summer warming (Table 3).

In the meadow habitat, all plant growth forms responded to enhanced snow (Table 4). Shrub abundance was significantly lower in both Medium and Deep than in Ambient 
Table 3. Parameter estimates from linear mixed effects models for abundance of each growth form (based on mean number of hits per plot) in a dry heath habitat on Svalbard, Norway.

\begin{tabular}{llllll}
\hline Treatment & Shrubs & Graminoids & Forbs & Bryophytes & Lichens \\
\hline Unmanipulated & $126.3(88.1,164.4)[28]$ & $6.0(2.0,10.0)[25]$ & $12.0(-0.9,24.9)[28]$ & $84.2(66.4,102.1)[29]$ & $7.5(1.9,13.1)[29]$ \\
Effect: Warming & $28.2(-5.9,62.4)[28]$ & $1.4(-2.5,5.3)[25]$ & $\mathbf{1 0 . 0}(1.1,18.8)^{*}[28]$ & $8.1(-12.2,28.3)[29]$ & $2.2(-2.2,6.7)[29]$ \\
Effect: Medium & $-38.8(-77.9,0.32)[8]$ & $1.2(-4.9,7.4)[8]$ & $1.2(-16.0,18.3)[8]$ & $6.6(-16.7,30.0)[8]$ & $-1.7(-8.5,5.1)[8]$ \\
Effect: Deep & $-\mathbf{1 0 1 . 1}(-139.5,-62.7)^{*}[8]$ & $0.9(-5.1,7.4)[8]$ & $\mathbf{9 . 5}(-7.8,26.9)[8]$ & $\mathbf{2 5 . 1}(1.7,48.4)^{*}[8]$ & $4.5(-2.3,11.3)[8]$ \\
\hline
\end{tabular}

Note: The first line of values represents the means in unmanipulated conditions (i.e., Ambient snow regime and no summer warming), including lower and upper $95 \%$

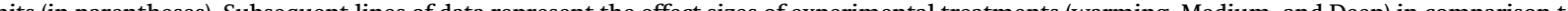
confidence ing (value in bold). 
Fig. 2. Growth form abundance, measured as the number of hits within each plot, in dry heath habitat in response to snow enhancement and summer warming. Estimates of means (grey bars) and their $95 \%$ confidence interval limits (whiskers) were deduced from linear mixed effects models for $(a)$ shrubs, $(b)$ forbs, and $(c)$ bryophytes. Statistically significant differences compared with Ambient without summer warming are marked with an asterisk $\left({ }^{*}, p<0.05\right)$.

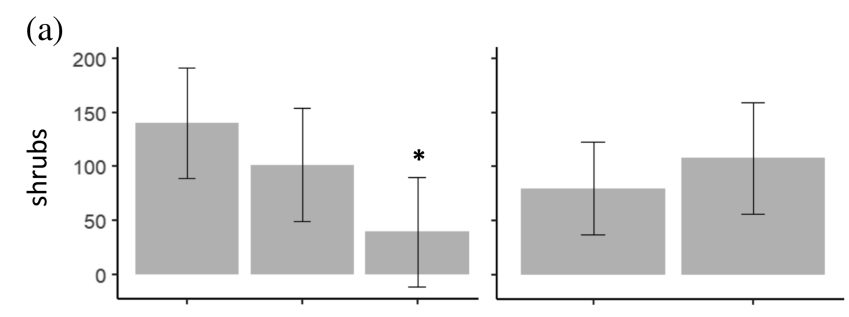

$$
\text { (b) }
$$

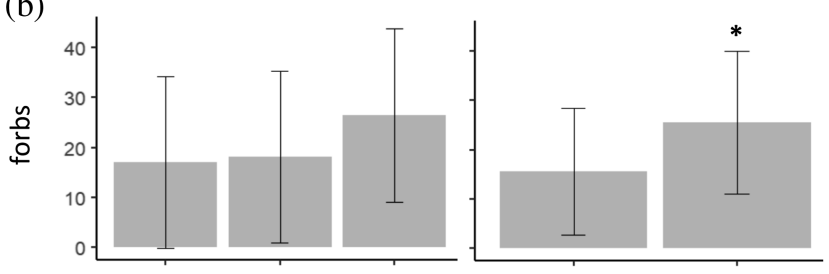

(c)

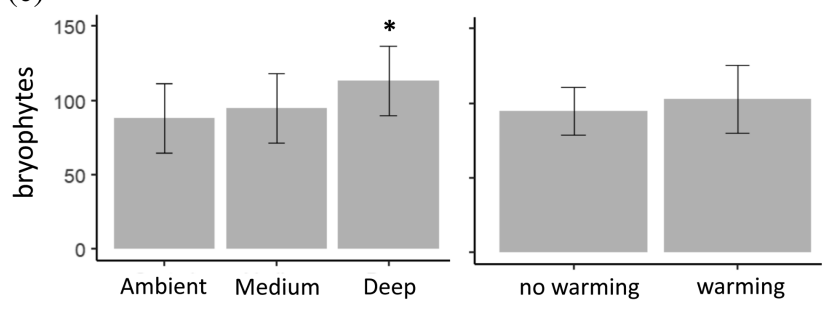

(Fig. 3a). Graminoid abundance was also lower in Deep than in Ambient (Table 4). Forbs had significantly greater abundance in Deep, but only in combination with summer warming (Fig. 3b). Bryophyte response also showed an interaction between snow enhancement and summer warming (Table 4). In plots without summer warming, bryophyte abundance was higher in Medium than in Ambient, but not in Deep. In plots with summer warming, bryophyte abundance was higher in both Medium and Deep (Fig. 3c). Lichen abundance was only affected by summer warming and was higher in warmed than in Ambient plots (Table 4). Bare ground increased with snow depth (Supplementary Fig. S1 ${ }^{1}$ ).

Within a growth form, not all species responded to snow regime in the same way (see Supplementary Table $\mathrm{S1}^{1}$ ). Furthermore, for some species, the size or direction of the response was habitat dependent. Interpretation of the responses of 52 species or groups is complicated and must be carried out with caution. However, we note that several moss species increased with snow depth (e.g., Sanionia uncinata, Polytrichum spp.), while some decreased (Hylocomium splendens) and others increased with snow in heath but decreased in meadow (Dicranum spp. and Distichium spp.).

Effects of winter and summer treatments on plant diversity

Heath vascular plant diversity responded only to snow regime and not to short-term summer warming. However, the effects depended on the diversity measure used (Table 5). Species richness of vascular plants was lower in Deep than in Ambient (Fig. 4a). We found 
Table 4. Parameter estimates from linear mixed effects models for abundance of each growth form (based on mean number of hits per plot) in a mesic meadow habitat on Svalbard, Norway (for key to the results see Table 3).

\begin{tabular}{|c|c|c|c|c|c|}
\hline Treatment & Shrubs & Graminoids & Forbs & Bryophytes & Lichens \\
\hline Unmanipulated & $111.8(87.0,136.5)[27]$ & $126.1(88.7,163.4)[27]$ & $18.0(8.8,27.2)[25]$ & $95.5(70.7,120.4)[25]$ & $6.4(2.3,10.5)[27]$ \\
\hline Effect: Warming & $17.6(-4.1,39.4)[27]$ & $0.9(-31.4,33.1)[27]$ & - & - & $3.6(0.3,6.9)^{*}[27]$ \\
\hline Effect: Medium & $-80.2(-106.4,-54.1)^{*}[7]$ & $-34.3(-94.4,25.9)[7]$ & - & - & $0.2(-5.2,5.5)[7]$ \\
\hline Effect: Deep & $-93.2(-117.4,-69.0)^{*}[7]$ & $-74.1(-130.7,-17.6)^{*}[7]$ & - & - & $-1.4(-6.4,3.5)[7]$ \\
\hline Effect: Medium (no warming) & - & - & $8.3(-5.4,22.1)[7]$ & $58.8(16.6,101.0)^{*}[7]$ & - \\
\hline Effect: Deep (no warming) & - & - & $7.6(-5.4,20.5)[7]$ & $-2.5(-42.2,37.2)[7]$ & - \\
\hline Effect: Medium (warming) & - & - & $10.9(-5.9,27.8)[7]$ & $75.9(28.9,123.0)^{*}[7]$ & - \\
\hline Effect: Deep (warming) & - & - & $25.6(9.7,41.5)^{*}[7]$ & $60.6(16.4,104.9) *[7]$ & - \\
\hline
\end{tabular}


Fig. 3. Growth form abundance, measured as the number of hits within each plot, in mesic meadow habitat in response to snow enhancement and summer warming. Estimates of $(a)$ mean shrub abundance (grey bars) and their 95\% confidence interval limits (whiskers) were deduced from linear mixed effects models. Statistically significant differences compared with Ambient without summer warming are marked with an asterisk $\left({ }^{*}, p<0.05\right)$. Treatment interactions affected estimates of $(b)$ forb and $(c)$ bryophyte abundance, and statistically significant effects of snow enhancement are separately presented for plots without (dark grey) and with (light grey) summer warming.
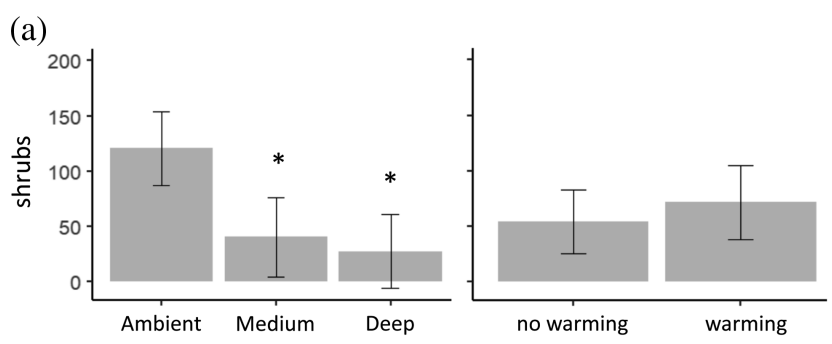

(b)
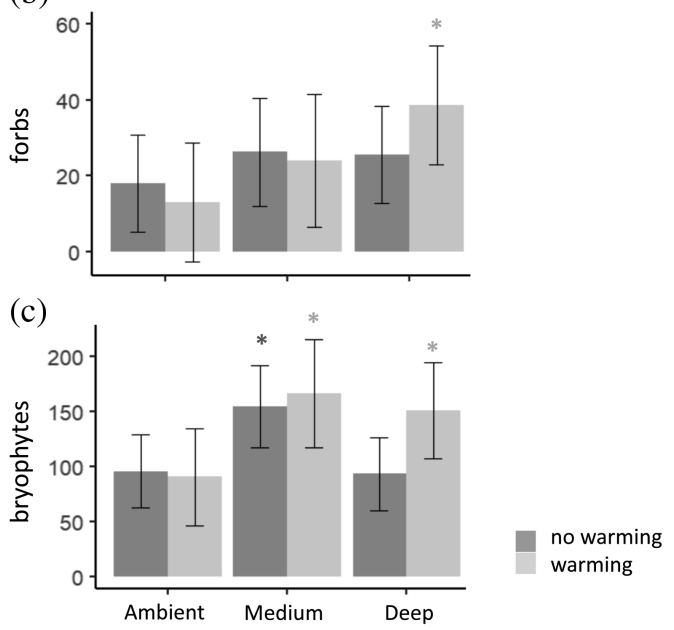

the same general pattern when including taxonomic units of bryophytes in the richness measure (Fig. $4 b$ ), as bryophyte richness did not respond to treatment. However, overall richness increased with summer warming (Table 5). The SDI of vascular plants and of bryophytes was not significantly affected by snow enhancement or summer warming (Table 5).

Meadow vascular plant species richness was only affected by snow enhancement and was lower in Deep than Ambient (Fig. 5a; Table 6). However, bryophyte richness only decreased in Deep for plots without summer warming and remained stable in enhanced snow regimes with summer warming (Table 6). Compared with Ambient, species richness including vascular plant and bryophyte taxa was only lower in Deep without summer warming (Fig. $5 b$; Table 6). The SDI of vascular plants was not affected by either of the treatments, but the SDI of bryophyte taxa showed the same response pattern as bryophyte richness (Table 6). 
Table 5. Parameter estimates from linear mixed effects models for diversity in a dry heath habitat on Svalbard, Norway (see Tables 3 and 4 for key to the results).

\begin{tabular}{lllllll}
\hline & \multicolumn{2}{l}{ Species richness } & & & \multicolumn{2}{l}{ Shannon diversity index } \\
\cline { 2 - 3 } \cline { 6 - 7 } Treatment & Vascular plants & Bryophytes & All & & Vascular plants \\
\hline Unmanipulated & $9.2(7.7,10.6)[29]$ & $6.3(5.6,7.0)[29]$ & $15.5(14.0,17.0)[29]$ & & $1.24(1.02,1.47)[29]$ & $1.33(1.14,1.52)[28]$ \\
Effect: Warming & $0.9(-0.2,2.1)[29]$ & $0.2(-0.5,0.9)[29]$ & $\mathbf{1 . 2}(0.0,2.3)^{*}[29]$ & & $0.04(-0.11,0.18)[29]$ & $0.07(-0.05,0.19)[28]$ \\
Effect: Medium & $-0.3(-2.4,1.7)[8]$ & $-0.4(-1.3,0.5)[8]$ & $-0.7(-3.1,1.6)[8]$ & & $0.11(-0.24,0.45)[8]$ & $-0.07(-0.34,0.18)[8]$ \\
Effect: Deep & $-\mathbf{2 . 9}(-5.0,-0.9)^{*}[8]$ & $-0.1(-1.0,0.9)[8]$ & $-\mathbf{3 . 0}(-5.4,-0.6)^{*}[8]$ & & $-0.15(-0.50,0.20)[8]$ & $-0.02(-0.27,0.24)[8]$ \\
\hline
\end{tabular}


Fig. 4. Plant diversity in dry heath habitat in response to snow enhancement and summer warming. Estimates of mean species richness (grey bars) and their 95\% confidence interval limits (whiskers) were deduced from linear mixed effects models for $(a)$ species richness of vascular plants and $(b)$ richness of the entire plant community. Statistically significant differences compared with Ambient without summer warming are marked with an asterisk (*, $p<0.05)$.
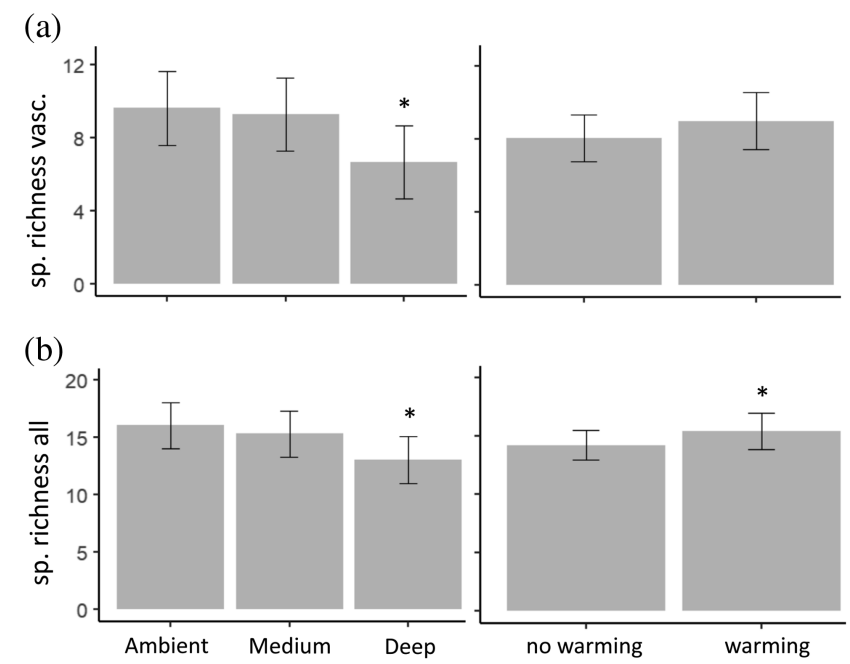

Fig. 5. Plant diversity in mesic meadow habitat in response to snow enhancement and summer warming. Estimates of $(a)$ vascular plant species richness (grey bars) and their 95\% confidence interval limits (whiskers) were deduced from linear mixed effects models. Statistically significant differences compared with Ambient without summer warming are marked with an asterisk $\left(^{*}, p<0.05\right)$. (b) Treatment interactions affected richness estimates of the entire plant community, and statistically significant effects of snow enhancement are separately presented for plots without (dark grey) and with (light grey) summer warming.
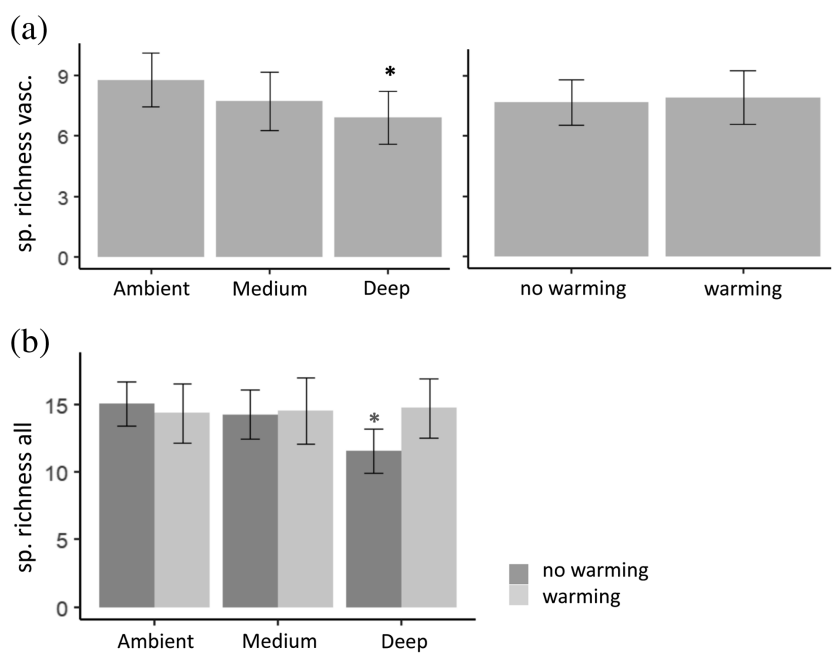
Table 6. Parameter estimates from linear mixed effects models for diversity in a mesic meadow habitat on Svalbard, Norway (see Tables 3-5 for key to the results).

\begin{tabular}{|c|c|c|c|c|c|}
\hline \multirow[b]{2}{*}{ Treatment } & \multicolumn{3}{|l|}{ Species richness } & \multicolumn{2}{|c|}{ Shannon diversity index } \\
\hline & Vascular plants & Bryophytes & All & Vascular plants & Bryophytes \\
\hline Unmanipulated & $8.7(7.6,9.7)[27]$ & $6.2(5.6,6.8)[25]$ & $15.1(13.9,16.3)[25]$ & $1.52(1.36,1.68)[27]$ & $1.48(1.38,1.58)[24]$ \\
\hline Effect: Warming & $0.3(-0.7,1.2)[27]$ & - & - & $0.08(-0.11,0.26)[27]$ & - \\
\hline Effect: Medium & $-1.1(-2.3,0.2)[7]$ & - & - & $0.00(-0.22,0.22)[7]$ & - \\
\hline Effect: Deep & $-1.9(-3.1,-0.7)^{*}[7]$ & - & - & $-0.13(-0.33,0.07)[7]$ & - \\
\hline Effect: Medium (no warming) & - & $0.3(-0.5,1.2)[7]$ & $-0.8(-2.4,0.8)[7]$ & - & $-0.07(-0.23,0.09)[7]$ \\
\hline Effect: Deep (no warming) & - & $-\mathbf{1 . 0}(-1.7,-0.3)^{*}[7]$ & $-3.5(-5.0,-2.0)^{*}[7]$ & - & $-0.3(-0.46,-0.14)^{*}[7]$ \\
\hline Effect: Medium (warming) & - & $1.0(-0.1,2.2)[7]$ & $0.2(-2.1,2.4)[7]$ & - & $0.07(-0.15,0.29)[7]$ \\
\hline Effect: Deep (warming) & - & $1.0(-0.1,2.1)[7]$ & $0.4(-1.7,2.5)[7]$ & - & $0.11(-0.09,0.31)[7]$ \\
\hline
\end{tabular}




\section{Discussion}

Habitat-specific treatment effects on plant community structure

Our results support hypothesis H1, namely that snow enhancement would change the abundance of plant growth forms and lichens and that responses of some growth forms would be habitat specific. Interaction effects of snow enhancement and short-term summer warming (hypothesis H2) were observed only within the meadow habitat.

The only growth forms that were consistently affected by snow enhancement in both habitats of our study were shrubs and bryophytes (Table 7). In general, shrub abundance was lower with enhanced snow, and bryophyte abundance was higher. These patterns of change are the opposite to that found at other Arctic sites in Canada and Alaska, where experimental snow enhancement often increased either evergreen or deciduous shrub abundance (Leffler et al. 2016; Christiansen et al. 2018). Such findings were usually related to elevated nutrient availability, which results from the higher depolymerization and mineralization rates that occur with enhanced snow (Schimel et al. 2004). Arctic plant communities that are dominated by shrubs were thus predicted to accumulate even more snow, causing a positive feedback loop of these mechanisms and enforcing shrub expansion (Sturm et al. 2005). Several of our findings indicate that such mechanisms cannot be generalized for the Arctic. Previous assessments have showed that elevated nutrient availability under enhanced snow regimes are also found at our site and that vascular plants show higher nitrogen uptake (Mörsdorf et al. 2019), increasing the growth of some species (Rumpf et al. 2014; Semenchuk et al. 2015). However, enhanced snow can also adversely affect vascular plant growth. Cooler summer soils (due to late melt and enhanced moisture, especially early in the season), together with reduced growing season length (due to late onset of green-up), negatively affect the vegetative and reproductive success of some vascular plants (Mallik et al. 2011; Semenchuk et al. 2013, 2016b). Shrub growth in particular may be impaired by the reduction of growing season length. Current shrubification trends in the Arctic can partly be attributed to warmer and longer growing seasons (Martin et al. 2017). The long-lasting snow cover under enhanced snow regimes at our high-latitude Arctic site may thus have a stronger impact on shortening overall growing season length for shrub growth compared with Arctic sites at lower latitudes, such as Toolik Lake (Leffler et al. 2016) or Daring Lake (Christiansen et al. 2018). Environmental conditions during the winter may also explain lower shrub abundance under enhanced snow regimes. Soil winter temperatures were significantly elevated owing to the insulating effect of enhanced snow, and plants with overwintering organs (stems, rhizomes, and roots, as well as preformed leaf and flower buds) experienced increased respiration rates and carbon loss during this season (Morgner et al. 2010; Semenchuk et al. 2016a). In this study, we cannot separate the effects of summer (reduced growing season length) and winter (increased carbon losses) mechanisms that may explain reduced shrub abundance under enhanced snow regimes. These mechanisms may also explain reduced graminoid abundance with snow enhancement in mesic meadows. Finally, snow-enhanced increases in soil moisture soon after snowmelt (Cooper et al 2011; Mörsdorf et al 2019) with associated anoxia may negatively alter conditions for shrubs that do not readily tolerate waterlogging (Leffler et al. 2016), especially in our poorly drained mesic habitat. In contrast, at Toolik Lake, long-term increases in shrub abundance with enhanced snow were related to increased drainage resulting from a deeper active layer (Leffler et al. 2016).

Both small-stature forbs and bryophytes may profit from reduced light competition from shrubs under enhanced snow regimes. However, the extent to which snow enhancements alter soil moisture conditions also seems to determine the extent to which changes in community structure are induced. High bryophyte abundance in meadow habitat was 
Table 7. Summary of the context dependencies of climate change effects on plant community properties.

\begin{tabular}{lllll}
\hline \multirow{2}{*}{ Habitat type } & Community property & $\begin{array}{l}\text { Enhanced } \\
\text { winter snow }\end{array}$ & $\begin{array}{l}\text { Summer } \\
\text { warming }\end{array}$ & $\begin{array}{l}\text { Interaction } \\
\text { effect }\end{array}$ \\
\hline Dry heath & Total shrub abundance & - & 0 & No \\
& Graminoid abundance & 0 & 0 & No \\
& Forb abundance & 0 & + & No \\
& Bryophyte abundance & + & 0 & No \\
& Lichen abundance & 0 & 0 & No \\
Mesic meadow & Total shrub abundance & - & 0 & No \\
& Graminoid abundance & - & 0 & No \\
& Forb abundance & $0 /+$ & + & Yes \\
& Bryophyte abundance & $+/-$ & + & Yes \\
& Lichen abundance & 0 & + & No \\
\hline Dry heath & Species richness of vascular plants & - & 0 & No \\
& Species richness of bryophytes & 0 & 0 & No \\
& Species richness all plants & - & + & No \\
& SDI of vascular plants & 0 & 0 & No \\
& SDI of bryophytes & 0 & 0 & No \\
Mesic meadow & Species richness of vascular plants & - & 0 & No \\
& Species richness of bryophytes & $-/ 0$ & + & Yes \\
& Species richness all plants & $-/ 0$ & + & Yes \\
& SDI of vascular plants & 0 & 0 & No \\
& SDI of bryophytes & $-/ 0$ & + & Yes \\
\hline
\end{tabular}

Note: The effects of either the Deep or Medium treatment are summarized as the effects of "enhanced winter snow". Those effects and the effects of summer warming are compared with unmanipulated conditions. Effects are presented separately for the dry heath and mesic meadow habitats. The "+" symbol represents positive effects of the respective parameter (i.e., an increase in the value of the respective community property), while the "-" symbol represents negative effects and "0" represents no significant effects. SDI, Shannon diversity index.

only registered in the Medium and not Deep regime, as long as no summer warming was applied. As outlined earlier, we generally assume that bryophytes profit from a release of vascular plant competition and an increase in nutrients and moisture under enhanced snow regimes (Cooper et al. 2019). However, the Deep regime has extremely long-lasting snow cover, which may promote the prevalence of diseases, such as parasitic fungi that can harm plants (Olofsson et al. 2011). Two host-specific fungal parasites Exobasidium hypogenum Nannfeldt on the vascular plant Cassiope tetragona and Pythium polare sp. nov. on mosses (especially Sanionia uncinata (Hedw.) Loeske) - both increased in response to enhanced snow at our site, and may be a factor driving vegetation change and increasing the amount of bare ground (Moriana-Armendariz et al. 2021). We can only speculate as to how short-term summer warming offsets the snow regime effect observed in Deep in our meadow habitat. We found that OTCs reversed the soil temperature decline from Ambient towards enhanced snow regimes (Fig. 1a). The reduced shrub abundance, and therefore soil shading, in Deep may enable the OTCs to warm the soil more effectively, providing a warmer environment that bryophytes can exploit since they are not moisture limited (Figs. $1 b$ and 1c), unlike in many other OTC experiments (Elmendorf et al. 2012b). Ameliorated growing conditions in our experiment included higher nutrient availability, which is known to be exploited by bryophytes (Sjögersten et al. 2010). These factors may help to compensate for losses caused by fungal pathogens under such conditions. These mechanisms need further research to be fully understood.

Forbs were also shown to benefit from short-term summer warming at our site. Increased forb abundance with summer warming is not a strongly pronounced response at most Arctic sites, also because warming often increases shrub abundance and light 
competition for small-stature forbs (Elmendorf et al. 2012b). In our dry heath habitat, we assume that such competition is less relevant than that at many other Arctic sites at lower latitudes, where general shrub abundance is higher. Many Arctic forb species are well adapted to the anoxia induced by enhanced snow depth (Crawford et al. 1994); in mesic meadows, small-stature forbs may thus profit from ameliorated environmental conditions characterized by a combination of high water supply and warm summer temperatures.

Since the vegetation structure of the habitats was different (Supplementary Table S1 ${ }^{1}$ ), it was not totally surprising that some responses were habitat dependent. This observation serves to remind us of the importance of including species lists for habitats when describing experimental results. As speculated by others (Leffler et al. 2016), we conclude that some Arctic plant communities may locally become more wet with enhanced snow depth and experience expansion of bryophytes (Epstein et al. 2000), rather than shrubs (Aerts et al. 2006; Christiansen et al. 2018), turning tundra vegetation into that more typical of a snow patch. The nature of the substrate and depth of the active layer are clearly important here in their influence on drainage. Such "bryofication" of Arctic plant communities may strongly affect ecosystem properties. Bryophytes can affect several ecosystem functions in the Arctic, including alterations of carbon, nitrogen, and water cycling (Lindo and Gonzalez 2010; Turetsky et al. 2012) or soil energy budgets (Gornall et al. 2007).

Habitat-specific treatment effects on within-community plant diversity

Our results support hypothesis $\mathrm{H} 3$, as we observed changes in plant community diversity in response to experimental treatments. In the meadow habitat, the inclusion of bryophyte taxa in diversity measures rendered overall plant diversity responses to be different from vascular plant diversity responses. Here, overall plant diversity was influenced by interaction effects between snow enhancement and summer warming, which may be explained by the response of bryophytes in this habitat.

These results are similar to findings from other Arctic (Wahren et al. 2005) and alpine (Scott and Rouse 1995; Seastedt and Vaccaro 2001; Litaor et al. 2008) sites, where vascular plant species richness decreased with enhanced snow. However, those studies attributed their diversity declines to increased shrub growth and competitive exclusion of smallstature plants (Wahren et al. 2005). Since we did not find such growth form responses at our site, we assume that other mechanisms are responsible for the declines in vascular plant species richness under snow enhancement. Many vascular plant growth forms, including shrubs, can promote biodiversity in the Arctic through their role as niche creators for other species (Bråthen and Ravolainen 2015). A loss of such nurse plants could thus lead to an overall loss of species within the community. Furthermore, our assessments in meadow habitat in particular showed that treatment effects on plant diversity depend on the plant taxa included in diversity measures.

When bryophytes were included in diversity measures, there was no decline in total plant richness under enhanced snow regimes for plots with summer warming. This treatment interaction corresponds to the bryophyte richness response to both treatments and may be explained by treatment-induced environmental changes, as outlined earlier. The results in the meadow habitat demonstrate that responses in vascular plant diversity might not necessarily reflect responses of overall plant diversity to climate change in the Arctic. We therefore assume that the outcomes we observed for bryophyte richness represent a rather conservative estimate of such effects, since we were not able to identify all bryophytes to the species level in the field. The overall richness of plant taxonomic units decreased by about four units in Deep snow regimes compared with those in Ambient. There are at least three species in the genera Plagiomnium, Pohlia, and Bryum in the surroundings of Longyearbyen (Prestø et al. 2014), and presumably some more bryophyte species, 
that we did not include in bryophyte richness values. We therefore assume that the actual effect of bryophytes on overall plant community richness is even stronger in reality than was estimated in our study. Changes in bryophyte richness in response to climate change are likely even greater than changes in vascular plant species richness. Monitoring of taxonomic information on bryophytes should therefore be a key feature in predicting Arctic plant diversity responses to climate change.

We acknowledge that abundance assessments of some bryophyte species are not possible in the field, and that a sensible classification of bryophytes into groups, relating to essential ecosystem functions in tundra, is thus far lacking but highly necessary. A current study is contributing to resolve this issue in the future (Lett et al. 2021). The SDI of bryophytes showed similar patterns as bryophyte richness in our study, but we urge researchers to be careful in calculating an SDI of overall plant diversity. The method of recording bryophytes in our plots differed slightly from recordings of vascular plant abundance. The latter were recorded three dimensionally through the canopy layer, which is nearly impossible for many small-stature bryophytes. Here, methodological studies are needed that provide a nondestructive approach to estimating vascular plant and bryophyte abundance on the same scale of units (e.g., g. $\mathrm{m}^{-2}$ ).

In conclusion, our results show that some plant community responses were consistent between both habitat types, such as the decrease in shrub abundance and vascular plant species richness with enhanced snow depth. Bryophyte abundance may also increase, but only up to a certain snow depth. However, most community responses were habitat specific. In the mesic meadow, we also found interaction effects of long-term snow enhancement and short-term summer warming, which affected plant growth form and diversity responses. The monitoring of bryophyte taxa deserves special attention with regard to environmental change scenarios, since bryophyte taxa may respond differently than vascular plants.

\section{Acknowledgements}

We are especially thankful to Anna Katharina Pilsbacher, Katariina Elsa Maria Vuorinen, Kathrin Bender, and Fumino Maruo for their help in the field.

\section{Funding statement}

This study was funded by the Research Council of Norway (“SnoEco" project No. 230970) and the Norwegian Centre for International Cooperation in Education (SIU) High North Programme ("JANATEX" project No. HNP2013/10092), both awarded to E.J.C. The article processing charge was funded by the University of Freiburg via the funding program "Open Access Publishing”.

\section{References}

ACIA. 2005. Arctic climate impact assessment. Cambridge University Press, UK.

Aerts, R., Cornelissen, J.H.C., and Dorrepaal, E. 2006. Plant performance in a warmer world: General responses of plants from cold, northern biomes and the importance of winter and spring events. Plant Ecol. 182: 65-77. doi: 10.1007/s11258-005-9031-1

Bråthen, K.A., and Ravolainen, V.T. 2015. Niche construction by growth forms is as strong a predictor of species diversity as environmental gradients. J. Ecol. 103(3): 701-713. doi: 10.1111/1365-2745.12380.

CAFF. 2013. Arctic biodiversity assessment. Status and trends in Arctic biodiversity. Conservation of Arctic Flora and Fauna, Akureyri, IS.

Callaghan, T.V., Björn, L.O., Chernov, Y., Chapin, T., Christensen, T.R., Huntley, B., et al. 2004. Biodiversity, distributions and adaptations of Arctic species in the context of environmental change. Ambio, 33(7): 404-417. doi: 10.1579/0044-7447-33.7.404. PMID: 15573569.

Callaghan, T.V., Johansson, M., Brown, R.D., Groisman, P.Y., Labba, N., Radionov, V., et al. 2011. The changing face of Arctic snow cover: A synthesis of observed and projected changes. Ambio, 40: 17-31. doi: 10.1007/s13280-0110212-y. 
CAVM Team. 2003. Circumpolar Arctic Vegetation Map. (1:7,500,000 Scale). U.S. Fish and Wildlife Service, Anchorage, Alaska Conservation of Arctic flora and fauna (CAFF), Map No. 1. Available from http://www. arcticatlas.org/maps/themes/cp/.

Christiansen, C.T., Lafreniére, M.J., Henry, G.H.R., and Grogan, P. 2018. Long-term deepened snow promotes tundra evergreen shrub growth and summertime ecosystem net $\mathrm{CO}_{2}$ gain but reduces soil carbon and nutrient pools. Glob. Chang. Biol. 24(8): 3508-3525. doi: 10.1111/gcb.14084. PMID: 29411950.

Cooper, E.J., Dullinger, S., and Semenchuk, P. 2011. Late snowmelt delays plant development and results in lower reproductive success in the High Arctic. Plant Sci. 180(1): 157-167. doi: 10.1016/j.plantsci.2010.09.005. PMID: 21421357.

Cooper, E.J., Little, C.J., Pilsbacher, A.K., and Mörsdorf, M.A. 2019. Disappearing green: Shrubs decline and bryophytes increase with nine years of increased snow accumulation in the High Arctic. J. Veg. Sci. 30(5): 857-867. doi: 10.1111/jvs.12793.

Crawford, R.M.M., Chapman, H.M., and Hodge, H. 1994. Anoxia tolerance in High Arctic vegetation. Arct. Alp. Res. 26(3): 308-312. doi: $10.2307 / 1551944$.

Elmendorf, S.C., Henry, G.H.R., Hollister, R.D., Björk, R.G., Boulanger-Lapointe, N., Cooper, E.J., et al. 2012a. Plotscale evidence of tundra vegetation change and links to recent summer warming. Nat. Clim. Chang. 2: 453-457. doi: 10.1038/nclimate1465.

Elmendorf, S.C., Henry, G.H.R., Hollister, R.D., Björk, R.G., Bjorkman, A.D., Callaghan, T.V., et al. 2012b. Global assessment of experimental climate warming on tundra vegetation: Heterogeneity over space and time. Ecol. Lett. 15(2): 164-175. doi: 10.1111/j.1461-0248.2011.01716.x. PMID: 22136670.

Elvebakk, A. 2005. A vegetation map of Svalbard on the scale 1:3.5 mill. Phytocoenologia, 35(4): 951-967. doi: 10.1127| 0340-269X/2005/0035-0951.

Epstein, H.E., Walker, M.D., Chapin, F.S., and Starfield, A.M. 2000. A Transient, nutrient-based model of Arctic plant community response to climatic warming. Ecol. Appl. 10(3): 824-841. doi: 10.1890/1051-0761(2000)010[0824: ATNBMO]2.0.CO;2.

Gornall, J.L., Jónsdóttir, I.S., Woodin, S.J., and Van Der Wal, R. 2007. Arctic mosses govern below-ground environment and ecosystem processes. Oecologia, 153: 931-941. doi: 10.1007/s00442-007-0785-0. PMID: 17618466.

Hjelle, A. 1993. Geology of Svalbard. Norwegian Polar Institute, Tromsø, Norway. Polarhåndbok 7.

Johansson, M., Callaghan, T.V., Bosiö, J., Åkerman, H.J., Jackowicz-Korczynski, M., and Christensen, T.R. 2013. Rapid responses of permafrost and vegetation to experimentally increased snow cover in Sub-Arctic Sweden. Environ. Res. Lett. 8(3): 035025. doi: 10.1088/1748-9326/8/3/035025.

Jonasson, S. 1988. Evaluation of the point intercept method for the estimation of plant biomass. Oikos, 52(1): 101-106. doi: $10.2307 / 3565988$.

Knight, D.H., Weaver, S.W., Starr, C.R., and Romme, W.H. 1979. Differential response of subalpine meadow vegetation to snow augmentation. J. Range Manage. 32(5): 356-359. doi: 10.2307/3898015.

Leffler, A.J., Klein, E.S., Oberbauer, S.F., and Welker, J.M. 2016. Coupled long-term summer warming and deeper snow alters species composition and stimulates gross primary productivity in tussock tundra. Oecologia, 181: 287-297. doi: 10.1007/s00442-015-3543-8. PMID: 26747269.

Lett, S., Jónsdóttir, I.S., Becker-Scarpitta, A., Christiansen, C.T., During, H., Ekelund, F., et al . 2021. Can bryophyte groups increase functional resolution in tundra ecosystems? Arct. Sci. In press. doi: 10.1139/as-2020-0057.

Lindo, Z., and Gonzalez, A. 2010. The bryosphere: An integral and influential component of the earth's biosphere. Ecosystems, 13: 612-627. doi: 10.1007/s10021-010-9336-3.

Litaor, M.I., Williams, M., and Seastedt, T.R. 2008. Topographic controls on snow distribution, soil moisture, and species diversity of herbaceous alpine vegetation, Niwot Ridge, Colorado. J. Geophys. Res. 113(G2). doi: 10.1029/ 2007JG000419.

Lupascu, M., Czimczik, C.I., Welker, M.C., Ziolkowski, L.A., Cooper, E.J., and Welker, J.M. 2018. Winter ecosystem respiration and sources of $\mathrm{CO}_{2}$ from the high Arctic tundra of Svalbard: Response to a deeper snow experiment. J. Geophys. Res.: Biogeosci. 123(8): 2627-2642. doi: 10.1029/2018jg004396.

Mallik, A.U., Wdowiak, J.V., and Cooper, E.J. 2011. Growth and reproductive responses of Cassiope tetragona, a circumpolar evergreen shrub, to experimentally delayed snowmelt. Arct. Antarct. Alp. Res. 43(3): 404-409. doi: 10.1657/1938-4246-43.3.404.

Marion, G.M., Henry, G.H.R., Freckman, D.W., Johnstone, J., Jones, G., Jones, M.H., et al. 1997. Open-top designs for manipulating field temperature in high-latitude ecosystems. Glob. Chang. Biol. 3(S1): 20-32. doi: 10.1111/j.13652486.1997.gcb136.x.

Martin, A.C., Jeffers, E.S., Petrokofsky, G., Myers-Smith, I., and Macias-Fauria, M. 2017. Shrub growth and expansion in the Arctic tundra: An assessment of controlling factors using an evidence-based approach. Environ. Res. Lett. 12(8): 085007. doi: 10.1088/1748-9326/aa7989.

Moriana-Armendariz, M., Abbandonato, H., Yamaguchi, T., Mörsdorf, M.A., Aares, K.H., Semenchuk, P.R., et al. 2021. Increased snow and cold season temperatures alter High Arctic parasitic fungi - host plant interactions. Arct. Sci. Available e-First. doi: 10.1139/as-2020-0027.

Morgner, E., Elberling, B., Strebel, D., and Cooper, E.J. 2010. The importance of winter in annual ecosystem respiration in the High Arctic: Effects of snow depth in two vegetation types. Polar Res. 29(1): 58-74. doi: 10.1111/j.17518369.2010.00151.x.

Mörsdorf, M.A., Baggesen, N.S., Yoccoz, N.G., Michelsen, A., Elberling, B., Ambus, P.L., and Cooper, E.J. 2019. Deepened winter snow significantly influences the availability and forms of nitrogen taken up by plants in High Arctic tundra. Soil Biol. Biochem. 135: 222-234. doi: 10.1016/j.soilbio.2019.05.009. 
Myers-Smith, I.H., Forbes, B.C., Wilmking, M., Hallinger, M., Lantz, T., Blok, D., et al. 2011. Shrub expansion in tundra ecosystems: Dynamics, impacts and research priorities. Environ. Res. Lett. 6(4): 045509. doi: 10.1088/1748-9326/ 6/4/045509.

Natali, S.M., Schuur, E.A.G., Webb, E.E., Pries, C.E.H., and Crummer, K.G. 2014. Permafrost degradation stimulates carbon loss from experimentally warmed tundra. Ecology, 95(3): 602-608. doi: 10.1890/13-0602.1. PMID: 24804439.

Olofsson, J., Ericson, L., Torp, M., Stark, S., and Baxter, R. 2011. Carbon balance of Arctic tundra under increased snow cover mediated by a plant pathogen. Nat. Clim. Chang. 1: 220-223. doi: 10.1038/nclimate1142.

Øvstedal, D., Tønsberg, T., and Elvebakk, A. 2009. The lichen flora of Svalbard. Sommerfeltia, 33(1): 1-393. doi: 10.2478/v10208-011-0013-5.

Pinheiro, J.C., and Bates, D.M. 2000. Mixed-effects models in S and S-PLUS. Springer Science+Business Media, New York, USA.

Prestø, T., Lüth, M., and Hassel, K. 2014. Bryophytes of the Longyearbyen area. NTNU Vitenskapsmuseet, Trondheim, NOR. Naturhistorisk notat, 10: 1-68. doi: 10.13140/RG.2.1.2426.7600.

Rumpf, S.B., Semenchuk, P.R., Dullinger, S., and Cooper, E.J. 2014. Idiosyncratic responses of High Arctic plants to changing snow regimes. PLoS ONE, 9(2): e86281. doi: 10.1371/journal.pone.0086281. PMID: 24523859.

Saha, S.K., Rinke, A., and Dethloff, K. 2006. Future winter extreme temperature and precipitation events in the Arctic. Geophys. Res. Lett. 33(15): 1-4. doi: 10.1029/2006GL026451.

Schimel, J.P., Bilbrough, C., and Welker, J.M. 2004. Increased snow depth affects microbial activity and nitrogen mineralization in two Arctic tundra communities. Soil Biol. Biochem. 36(2): 217-227. doi: 10.1016/ j.soilbio.2003.09.008.

Scott, P.A., and Rouse, W.R. 1995. Impacts of increased winter snow cover on upland tundra vegetation: A case example. Clim. Res. 5(1): 25-30. doi: 10.3354/cr005025.

Seastedt, T.R., and Vaccaro, L. 2001. Plant species richness, productivity, and nitrogen and phosphorus limitations across a snowpack gradient in Alpine tundra, Colorado, USA. Arct. Antarc. Alp. Res. 33(1): 100-106. doi: 10.1080/ 15230430.2001.12003410.

Semenchuk, P.R., Elberling, B., and Cooper, E.J. 2013. Snow cover and extreme winter warming events control flower abundance of some, but not all species in High Arctic Svalbard. Ecol. Evol. 3(8): 2586-2599. doi: 10.1002/ ece3.648. PMID: 24567826.

Semenchuk, P.R., Elberling, B., Amtorp, C., Winkler, J., Rumpf, S., Michelsen, A., and Cooper, E.J. 2015. Deeper snow alters soil nutrient availability and leaf nutrient status in High Arctic tundra. Biogeochemistry, 124: 81-94. doi: 10.1007/s10533-015-0082-7.

Semenchuk, P.R., Christiansen, C.T., Grogan, P., Elberling, B., and Cooper, E.J. 2016a. Long-term experimentally deepened snow decreases growing-season respiration in a Low- and High-Arctic tundra ecosystem. J. Geophy. Res.: Biogeosci. 121(5): 1236-1248. doi: 10.1002/2015JG003251.

Semenchuk, P.R., Gillespie, M.A.K., Rumpf, S.B., Baggesen, N., Elberling, B., and Cooper, E.J. 2016b. High Arctic plant phenology is determined by snowmelt patterns but duration of phenological periods is fixed: An example of periodicity. Environ. Res. Lett. 11(12): 125006. doi: 10.1088/1748-9326/11/12/125006.

Sjögersten, S., Kuijper, D.P.J., van der Wal, R., Loonen, M.J.J.E., Huiskes, A.H.L., and Woodin, S.J. 2010. Nitrogen transfer between herbivores and their forage species. Polar Biol. 33: 1195-1203. doi: 10.1007/s00300-010-0809-9.

Strebel, D., Elberling, B., Morgner, E., Knicker, H.E., and Cooper, E.J. 2010. Cold-season soil respiration in response to grazing and warming in High-Arctic Svalbard. Polar Res. 29(1): 46-57. doi: 10.1111/j.1751-8369.2010.00154.x.

Sturm, M., Schimel, J., Michaelson, G., Welker, J.M., Oberbauer, S.F., Liston, G.E., et al. 2005. Winter biological processes could help convert Arctic tundra to shrubland. BioScience, 55(1): 17-26. doi: 10.1641/0006-3568(2005) 055[0017:WBPCHC]2.0.CO;2.

Tolgensbakk, J., Soerbel, L., and Hoegvard, K. 2000. Adventdalen, Geomorphological and Quaternary Geological Map, Svalbard 1:100000. Spitsbergen Sheet C9Q. Norsk Polarinstitutt, Tromsø, Norway. Temakart Nr. 32.

Turetsky, M.R., Bond-Lamberty, B., Euskirchen, E., Talbot, J., Frolking, S., McGuire, A.D., and Tuittila, E.S. 2012. The resilience and functional role of moss in boreal and Arctic ecosystems. New Phytol. 196(1): 49-67. doi: 10.1111/ j.1469-8137.2012.04254.x. PMID: 22924403.

van der Wal, R., Madan, N., van Lieshout, S., Dormann, C., Langvatn, R., and Albon, S.D. 2000. Trading forage quality for quantity? Plant phenology and patch choice by Svalbard reindeer. Oecologia, 123: 108-115. doi: 10.1007/s004420050995. PMID: 28308735.

Wahren, C.-H.A., Walker, M.D., and Bret-Harte, M.S. 2005. Vegetation responses in Alaskan Arctic tundra after 8 years of a summer warming and winter snow manipulation experiment. Glob. Chang. Biol. 11(4): 537-552. doi: 10.1111/j.1365-2486.2005.00927.x.

Wipf, S., and Rixen, C. 2010. A review of snow manipulation experiments in Arctic and Alpine tundra ecosystems. Polar Res. 29(1): 95-109. doi: 10.1111/j.1751-8369.2010.00153.x.

Zamin, T.J., and Grogan, P. 2012. Birch shrub growth in the low Arctic: The relative importance of experimental warming, enhanced nutrient availability, snow depth and caribou exclusion. Environ. Res. Lett. 7(3): 034027. doi: $10.1088 / 1748-9326 / 7 / 3 / 034027$. 